\title{
ВЛИЯНИЕ ФАКТОРОВ ПРОГРЕССИИ ДИАБЕТИЧЕКОЙ РЕТИНОПАТИИ НА СОДЕРЖАНИЕ МАРКЕРА АДГЕЗИВНОЙ ДИСФУНКЦИИ ЭНДОТЕЛИЯ VСАМ-1 В КРОВИ ПРИ САХАРНОМ ДИАБЕТЕ 2-ГО ТИПА КАК КЛАСТЕРА МЕТАБОЛИЧЕСКОГО СИНДРОМА
}

\begin{abstract}
Изучено содержание молекулы сосудистой клеточной адгезии VCAM-1 в крови на различных стадиях диабетической ретинопатии (ДРП) и проведена оценка влияния факторов прогрессии ДРП на её уровень в крови при метаболическом синдроме (МС). Исследования проведены у 64-х пациентов (95 глаз) с сахарным диабетом (СД) 2-го типа и ДРП (возраст $61,55 \pm 2,37$ года, продолжительность заболевания диабетом $11,23 \pm 2,11$ года, уровень НbA1C $9,89 \pm 0,78 \%$, ИМТ $34,55 \pm 3,75 \kappa 2 / \mathrm{m}^{2}$ ) и 23 -х лиц с ожирением без диабета (возраст $62,47 \pm 4,73$ года, ИМТ $31,87 \pm 3,92 \kappa 2 / \mathrm{M}^{2}$ ). Статистическую обработку проводили с помощью дисперсионного и регрессионного анализов. Выявлено, что показатели VCAM-1 крови превышали нормальные значения как в контрольной группе, так и на всех стадиях ДРП с наибольшим значением на 1-й стадии ДРП $(3,45 \pm 0,39$ nг/мл). Независимо от стадии ДРП выявлена достоверная прямая линейная зависимость между VCAM-1 и фибриногеном крови $(\mathrm{r}=0,59$; $\left.\mathrm{R}^{2}=35,1 \% ; \mathrm{p}=0,01\right)$ и тенденция к прямой зависимости содержания VCAM-1 от продолжительности заболевания СД 2-го типа $\left(\mathrm{r}=0,25 ; \mathrm{R}^{2}=6,5 \%, \mathrm{p}=0,05\right)$. Сделан вывод о возможном участии VCAM-1 вместе с фибриногеном в формировании лейкостаза и капиллярной окклюзии, особенно на непролиферативной стадии ДРП.
\end{abstract}

Ключевые слова: диабетическая ретинопатия, VCAM-1, сахарный диабет 2-го типа, метаболический синдром.

Одну из ключевых позиций в развитии диабетической ретинопатии (ДРП) занимает капиллярная окклюзия, однако точный механизм её возникновения остаётся неуточнённым. Отсутствие капиллярной перфузии является отличительным признаком ДРП, которая со временем развивается практически у всех больных диабетом [3]. Закрытие капилляров считается потенциальной ключевой причиной прогрессирования ДРП к более тяжёлым формам, а именно - к пролиферативной ДРП, при которой происходит неоваскуляризация и развитие ишемической диабетической макулопатии [8]. Согласно более ранним исследованиям считается, что различные отклонения реологических свойств крови при СД играют важную роль в отсутствии капиллярной перфузии. Они включают в себя сниженный кровоток в сетчатке [19], увеличенную вязкость крови [20] и агрегацию тромбоцитов [27].

За последнее время обнаруживается всё больше и больше доказательств ключевой роли лейкоцитов в отсутствии капиллярной перфузии. Предлагается в качестве возможного механизма этого явления увеличение адгезии лейкоцитов к эндотелию из-за повышенной экспрессии адгезивных молекул в микроцир- куляторном русле сетчатки (Vascular Cell Adhesion Molecule 1 - VCAM-1, Inter-Cellular Adhesion Molecule 1 - ICAM-1, Е-селектина, Р-селектина), маркерами которых являются CD31 (панэндотелиальный маркер) и эндотелиальный антиген PAL-E (маркер васкулярного просачивания) [28]. Таким образом показана увеличенная диффузная иммунореактивность ICAM-1 в сетчатке больных СД [15]. Было также показано, например, то, что растворимая ICAM-1 действует как ангиогенный фактор, который стимулирует хемокинетическую миграцию эндотелиальных клеток, их дифференциацию и ангиогенез in vitro и в естественных условиях [9]. При СД 2-го типа уровни sVCAM-1 и sE-селектина повышаются как у пациентов с микро-, так и с макрососудистыми осложнениями, тогда как уровни SICAM-1 выше только в группе микрососудистых осложнений [24]. Это предполагает потенциальную дифференцированную регуляцию молекул адгезии и, возможно, также их различные функции. Наличие растворимой ICAM-1 может служить индикатором про-ангиогенной среды в сетчатке, а растворимой VCAM-1 - маркером адгезивной дисфункции эндотелия, что определяет их важную роль 
в патогенезе сосудистых повреждений при метаболическом синдроме (МС) $[6,34]$. Исследования показали ассоциации между SVCAM-1 в сыворотке человека и пролиферативной ДРП, но не для sICAM-1 [13, 26]. ICAM-1 широко используется в качестве маркера активации эндотелия в экспериментальных исследованиях ДРП, но в этом контексте известно гораздо меньше данных о VCAM-1 [12]. Соответственно, является актуальной оценка потенциальных изменений VCAM-1 в клинической практике у больных с ДРП.

Цель исследования: изучить содержание молекулы сосудистой клеточной адгезии VCAM-1 в крови на различных стадиях ДРП и провести оценку влияния факторов прогрессии ДРП на содержание VCAM1 в крови при СД 2-го типа.

Материалы и методы. Исследования проведены у 64-х пациентов (95 глаз) с МС и ДРП (мужчины и женщины, средний возраст 61,55 2 2,37 года, средняя продолжительность заболевания диабетом 11,23 $\pm 2,11$ года, средний уровень гликированного гемоглобина

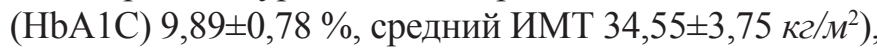
которых разделили на 3 группы в зависимости от стадии ДРП. Контрольная группа состояла из 23-х лиц с ожирением без диабета (мужчины и женщины, сред-

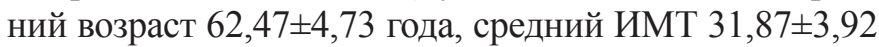
$\left.\kappa 2 / \mathrm{M}^{2}\right)$. Работа выполнена в соответствии с требованиями Хельсинкской декларации Всемирной медицинской ассоциации (2008), приказами МЗ Украины № 281 от 01.11.2000, № 355 от 25.09.2002, № 1118 от 21.12.2012 г. Включение или невключение в исследование пациентов и волонтёров осуществляли согласно принятым в литературе рекомендациям [1]. У пациентов исследуемой и контрольной групп измеряли рост, массу тела, объём талии и бёдер, рассчитывали индекс массы тела (ИМТ), регистрировали систолическое и диастолическое артериальное давление, в сыворотке крови определяли концентрации общего холестерина, холестерина липопротеидов высокой плотности (ХС ЛПВП), холестерина липопротеидов низкой (ХС ЛПНП) и триглицеридов (ТГ), а также уровни глюкозы натощак и $\mathrm{HbA1C}$ (у пациентов с СД 2-го типа). МС определяли по Рабочим критериям экспертов Национального института здоровья США (Adult Treatment Panel III - ATP III) (2001), признанным ВО3 [7, 11]. Концентрацию глюкозы в плазме крови определяли глюкозооксидазным методом, а в капиллярной крови - ферментативным колориметрическим методом, концентрацию $\mathrm{HbA1C}$ в крови - методом жидкостной ионообменной хроматографии высокого давления, концентрацию ТГ, общего ХС и его фракций - спектрофотометрическим методом, фибриногена сыворотки крови - клоттинговым методом. Содержание VCAM в крови определяли методом иммуноферментного анализа (ИФА) с помощью набора "Human sVCAM-1 ELISA kit”. Для сравнения полученных данных соглас- но инструкции набора нами была выбрана усреднённая норма в 1,09 мкг/мл (1090 нг/мл). Концентрацию IL-8 в плазме крови определяли методом ИФА с помощью набора “Human Interleukin-8 ELISA kit”. Уровнем сравнения НbA1C с учётом пациент-ориентированного подхода и ожидаемой продолжительности жизни был избран менее 8 \% [16, 30]. Выделяли следующие типы антидиабетической терапии: 1 - диета и приём пероральных сахароснижающих препаратов (ПССП), 2 - инсулинотерапия. Всем пациентам проводилось комплексное офтальмологическое обследование с применением авторефрактометрии, визометрии, тонометрии, периметрии, биомикроскопии, фотографирования глазного дна и флюоресцентной ангиографии глазного дна (по показаниям). Диагноз ДРП выставляли согласно Приказа МЗ Украины от 22.05.2009 № 356 в редакции Приказа МЗ Украины от 05.08.2009 № 574, в котором рекомендовано выделять 3 основных стадии ДРП по [18]: непролиферативную, препролиферативную и пролиферативную. Для оптимизации полученных данных при оценке влияния факторов прогрессии СД 2-го типа пре- и пролиферативную стадии ДРП мы условно объединяли в одну стадию. Статистическую обработку проводили с помощью одно- и двухфакторного дисперсионного анализа и регрессионного анализа. Применяли параметрический критерий Фишера или непараметрический критерий Крускала-Уоллиса. Характеристиками регрессионных моделей считали: $r$ - коэффициент корреляции, $R^{2}$ - коэффициент детерминации, $p$ - уровень статистической значимости моделей. Статистические характеристики представлены в виде среднего арифметического (М) и стандартной ошибки $( \pm \mathrm{m}), 95$ \%-го доверительного интервала (95\%-й ДИ). Статистически значимыми считали различия, если $\mathrm{p}<0,05$. Статистический анализ данных проводился с помощью компьютерной программы “SPSS 9.0”. Вычисления и построение графиков кривых проводилось в статистическом компьютерном пакете "Statgraphics 3" для Windows.

Результаты и их обсуждение. Как показали результаты дисперсионного анализа, средние показатели VCAM-1 крови превышали усреднённую норму $(1,09$ мкг/мл) и её нижний ДИ (0,68 мкг/мл) как в контрольной группе (лица с ожирением), так и на всех стадиях ДРП с наибольшим средним значением при ожирении $(3,18 \pm 0,53$ мкг/мл) и на I-й стадии ДРП $(3,45 \pm 0,39$ нг/мл) (в том числе и по ДИ - 3,93 мкг/мл и 4,0 мкг/мл соответственно). Отмечено снижение содержания VCAM-1 в крови на $I I-\check{u}$ и $I I I-\breve{u}$ стадиях ДРП по сравнению с I-й стадией и контролем (табл. 1). Если при ожирении степень превышения уровня VCAM-1 составляла 3,1 раза (по ДИ - 3,9 раза), то на II-й и III-й стадиях ДРП степень превышения референсных значений была несколько меньшей и составляла 2,2 раза и 2,6 раза соответственно 
Среднестатистические показатели уровня VCAM-1 крови на разных стадиях диабетической ретинопатии (N; M+m; 95 \% ДИ)

\begin{tabular}{|c|c|c|c|c|c|}
\hline \multirow{2}{*}{ Показатель } & \multirow{2}{*}{$\begin{array}{c}\text { Статистический } \\
\text { показатель }\end{array}$} & \multirow{2}{*}{ Ожирение } & \multicolumn{3}{|c|}{ Диабетическая ретинопатия } \\
\hline & & & I-я стадия & II-я стадия & III-я стадия \\
\hline VCAM-1, мкг/мл & $\begin{array}{c}\mathrm{N} \\
\mathrm{M} \pm \mathrm{m} \\
95 \% \text {-й ДИ }\end{array}$ & $\begin{array}{c}23 \\
3,18 \pm 0,53 \\
2,44-3,93\end{array}$ & $\begin{array}{c}42 \\
3,45 \pm 0,39 \\
2,89-4,00\end{array}$ & $\begin{array}{c}12 \\
2,21 \pm 0,84 \\
1,02-3,39\end{array}$ & $\begin{array}{c}10 \\
2,60 \pm 0,89 \\
1,34-3,86\end{array}$ \\
\hline
\end{tabular}

Примечания:

$\mathrm{N}$ - количество исследуемых;

ДИ - доверительный интервал

(по ДИ - 3,3 раза и 3,8 раза соответственно), но эти изменения не были статистически значимыми.

Показатели содержания VCAM-1 в крови больных с учётом факторов прогрессии ДРП представлены в табл. 2. Двухфакторный дисперсионный анализ позволил выявить ряд особенностей, связанных с факторами риска прогресии ДРП. Так, в возрасте до 60-ти лет наибольший средний уровень VCAM-1 был на $I-\breve{u}$ стадии ДРП, а в возрасте свыше 60-ти лет - тоже на I-й стадии ДРП. Наихудший уровень VCAM-1 в данных группах сравнения наблюдался у пациентов в возрасте свыше 60-ти лет на I-й стадии ДРП (4,26 пг/мл, а по ДИ - 5,12 мкг/мл) (данные достоверны по сравнению с возрастом больных до 60-ти лет на I-й стадии ДРП). По результатам регрессионного анализа нам не удалось выявить взаимосвязи VCAM-1 с возрастом в какой-либо выборке исследуемых больных ДРП.

У пациентов с продолжительностью заболевания диабетом до 10-ти лет средний уровень VCAM-1 был ровным на всех стадиях ДРП с небольшим увеличением на I-й стадии, а у больных с продолжительностью заболевания диабетом более 10-ти лет наибольший уровень VCAM-1 был на I-й стадии ДРП. Наихудший средний уровень VCAM-1 в данных группах сравнения отмечается у пациентов с продолжительностью заболевания диабетом более 10-ти лет на I-й стадии ДРП (5,06 мкг/мл, а по ДИ - 6,05 мкг/мл) (данные достоверны по сравнению с продолжительностью заболевания диабетом до 10-ти лет на I-й стадии ДРП, p<0,01).

Учитывая результаты регрессионного анализа, можно утверждать о наличии у пациентов с ДРП отчётливой тенденции $(\mathrm{p}=0,05)$ слабой прямой зависимости $\left(\mathrm{r}=0,25 ; \mathrm{R}^{2}=6,5 \%, \mathrm{~N}=58\right)$ содержания VCAM-1 от продолжительности заболевания СД 2-го типа.

$\mathrm{Y}$ больных с уровнем $\mathrm{HbA} 1 \mathrm{C} \leq 8$ \% преимущественно наибольший средний уровень VCAM-1 был у пациентов на I-й стадии ДРП, а при НbA1C более $8 \%$ более отчётливо - также на I-й стадии ДРП. Наихудший средний уровень VCAM-1 в данных группах сравнения наблюдался у больных с НbA1C>8 \% на I-й стадии ДРП (3,67 мкг/мл, по ДИ 4,38 мкг/мл). По данным регрессионного анализа не было выявлено статистически значимой зависимости содержания VCAM-1 от уровня HbA1c.
При терапии ПССП наибольший средний уровень VCAM-1 был у пациентов на I-й стадии ДРП, а при использовании инсулинотерапии - также на I-й стадии ДРП. Наихудший средний уровень VCAM-1 в представленных группах сравнения отмечался также на I-й стадии ДРП у больных, получающих инсулинотерапию (4,7 мкг/мл, а по ДИ - 5,56 мкг/мл).

Примечательно, что у больных с СД 2-го типа, находящихся на инсулинотерапии, средний показатель VCAM1 был статистически значимо выше, чем у больных СД 2-го типа, принимающих ПССП ( $<00,01)$. Дополнительно статистически значимо $(\mathrm{p}<0,01)$ более высокий уровень VCAM-1 на фоне инсулинотерапии отмечался у

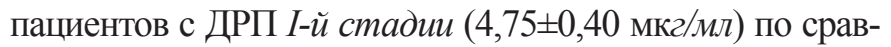

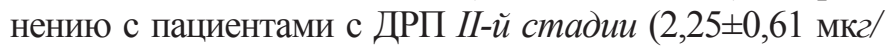
мл, $\mathrm{p}<0,01)$ и условно объединенной II-й+III-й стадией ДРП $(2,53 \pm 0,46$ мкг/мл, $<<0,01)$ и группой лиц с ожире-

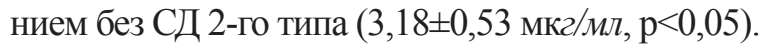

В группе больных с $\mathrm{MC}(\mathrm{N}=17)$ на $I I-\breve{u}+I I I-\breve{u} c m a-$ дии ДРП была отмечена прямая зависимость концентрации фибриногена от содержания VCAM-1. Регрессионная кривая с параметрами $\left(\mathrm{r}=0,59 ; \mathrm{R}^{2}=35,1 \%\right.$; $\mathrm{p}=0,01)$ представлена на рисунке.

Принято считать, что дисфункция эндотелия и повышение уровня провоспалительных цитокинов и молекул адгезии способствуют лейкостазу путем усиления взаимодействия лейкоцитов и эндотелиальных клеток $[21,29]$. Эндотелиальные клетки выделяют множество провоспалительных медиаторов и экспрессируют различные молекулы адгезии - такие как ICAM-

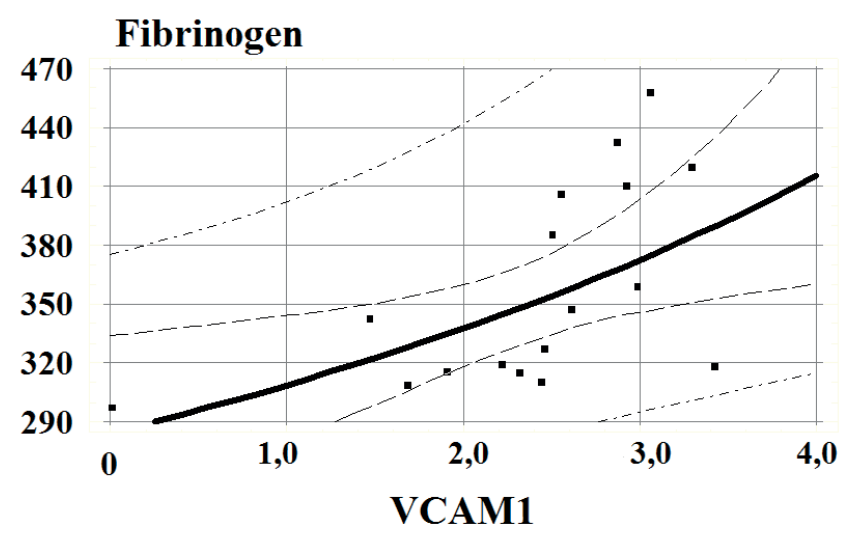

Puc. Кривая зависимости концентрации фибриногена от VCAM-1 на II-й+III-й стадиях диабетической ретинопатии 
Среднестатистические данные концентрации VCAM-1 крови на разных стадиях диабетической ретинопатии в зависимости от факторов её прогрессии (N; M $\pm \mathbf{m} ; 95 \%$-й ДИ)

\begin{tabular}{|c|c|c|c|}
\hline \multirow{2}{*}{ Группы сравнения } & \multicolumn{3}{|c|}{ Диабетическая ретинопатия } \\
\hline & I-я стадия & II-я стадия & III-я стадия \\
\hline $\begin{array}{c}\text { Возраст пациентов } \\
\leq 60 \text { лет }\end{array}$ & $\begin{array}{c}25 \\
2,89 \pm 0,35 \\
2,18-3,61\end{array}$ & $\begin{array}{c}6 \\
1,89 \pm 1,02 \\
-0,16-3,95\end{array}$ & $\begin{array}{c}5 \\
2,46 \pm 0,88 \\
0,68-4,24\end{array}$ \\
\hline $\begin{array}{c}\text { Возраст пациентов } \\
>60 \text { лет }\end{array}$ & $\begin{array}{c}17 \\
4,26 \pm 0,43 \\
3,39-51,2 \\
\mathrm{P}<0,01 * \\
\end{array}$ & $\begin{array}{c}6 \\
2,36 \pm 0,72 \\
0,91-3,82\end{array}$ & $\begin{array}{c}5 \\
2,76 \pm 0,88 \\
0,95-4,52\end{array}$ \\
\hline $\begin{array}{c}\text { Продолжительность заболевания } \\
\text { диабетом } \\
\leq 10 \text { лет }\end{array}$ & $\begin{array}{c}31 \\
2,87 \pm 0,29 \\
2,28-3,46\end{array}$ & $\begin{array}{c}6 \\
2,27 \pm 0,83 \\
0,60-3,95\end{array}$ & $\begin{array}{c}6 \\
2,47 \pm 0,74 \\
0,97-3,97\end{array}$ \\
\hline $\begin{array}{c}\text { Продолжительность заболевания } \\
\text { диабетом } \\
>10 \text { лет }\end{array}$ & $\begin{array}{c}11 \\
5,06 \pm 0,49 \\
4,06-6,05 \\
\mathrm{P}<0,01 * *\end{array}$ & $\begin{array}{c}7 \\
2,15 \pm 0,74 \\
0,65-3,65\end{array}$ & $\begin{array}{c}4 \\
2,82 \pm 0,96 \\
0,88-4,75\end{array}$ \\
\hline $\mathrm{HbA}_{1 \mathrm{C}} \leq 8 \%$ & $\begin{array}{c}15 \\
2,96 \pm 0,48 \\
1,98-3,94\end{array}$ & $\begin{array}{c}5 \\
1,23 \pm 1,31 \\
-1,40-3,86\end{array}$ & $\begin{array}{c}4 \\
2,58 \pm 1,07 \\
0,43-4,73\end{array}$ \\
\hline $\mathrm{HbA}_{1 \mathrm{C}}>8 \%$ & $\begin{array}{c}27 \\
3,67 \pm 0,35 \\
2,96-4,38 \\
\end{array}$ & $\begin{array}{c}7 \\
2,48 \pm 0,70 \\
1,08-3,89 \\
\end{array}$ & $\begin{array}{c}6 \\
2,61 \pm 0,83 \\
0,94-4,28\end{array}$ \\
\hline ПССП & $\begin{array}{c}26 \\
2,64 \pm 0,31 \\
2,01-3,27\end{array}$ & $\begin{array}{c}5 \\
2,06 \pm 1,15 \\
-0,25-4,37\end{array}$ & $\begin{array}{c}4 \\
2,04 \pm 0,94 \\
0,15-3,93\end{array}$ \\
\hline Инсулинотерапия & $\begin{array}{c}16 \\
4,75 \pm 0,40 \\
3,95-5,56 \\
\mathrm{P}<0,01 * * *\end{array}$ & $\begin{array}{c}7 \\
2,25 \pm 0,61 \\
1,01-3,48 \\
P_{1}<0,01\end{array}$ & $\begin{array}{c}6 \\
2,93 \pm 0,72 \\
1,47-4,40\end{array}$ \\
\hline
\end{tabular}

Примечания:

$\mathrm{N}$ - количество исследуемых;

ДИ - доверительный интервал;

ПССП - пероральные сахароснижающие препараты;

$\mathrm{p}$ - достоверность различий (F-критерий):

* - по сравнению с возрастом пациентов до 60 лет;

** - по сравнению с продолжительностью заболевания диабетом до 10 лет;

*** - по сравнению с ПССП;

1 - по сравнению с І-й стадией ретинопатии

1, VCAM-1, Р- и Е-селектины [17]. Эти мембранные белки необходимы для закрепления лейкоцитов на стенке сосуда и хорошо известны в качестве маркеров эндотелиальной дисфункции при воспалительных состояниях, таких как атеросклероз [22, 25, 31, 32]. Растворимые формы этих молекул адгезии и селектинов были обнаружены в сыворотке пациентов с диабетом, что свидетельствует о том, что они могут играть роль в диабетической эндотелиальной активации $[4,10,17]$. Более того, повышенные уровни растворимой формы VCAM-1 были выявлены в стекловидном теле у пациентов с диабетом $[2,5,14,23]$.

Наши результаты показали превышение усреднённой нормы VCAM-1 в крови во всех группах сравнения и в контроле с некоторым снижением его содержания на пре- и пролиферативной стадиях ДРП, что указывает на наличие характерной для $\mathrm{MC}$ адгезив- ной дисфункции эндотелия разной степени выраженности на всех стадиях ДРП.

Более детальный и углублённый анализ состояния клеточной эндотелиальной адгезии выявил на непролиферативной стадии ДРП относительно наибольший уровень VCAM-1 в возрасте пациентов более 60-ти лет (превышение рекомендуемых нормальных значений в 4,3 раза), при декомпенсации диабета (превышение нормальных значений в 3,6 раза), достоверное $(\mathrm{p}<0,01)$ возрастание концентрации VCAM-1 в крови у пациентов с увеличением возраста больных $(\mathrm{p}<0,01)$, длительности при сравнении группы инсулинотерапии с контролем $(\mathrm{p}<0,05)$.

На препролиферативной стадии ДРП обнаружено статистически значимое уменьшение уровня VCAM1 в крови по сравнению с непролиферативной стадией ДРП в группе инсулинотерапии $(\mathrm{p}<0,01)$. 
А по результатам регрессионного анализа можно говорить о наличии, независимо от стадии ДРП, отчётливой тенденции $(\mathrm{p}=0,05)$ к прямой зависимости содержания VCAM-1 от продолжительности заболевания СД 2-го типа, достоверной прямой зависимости между VCAM-1 и фибриногеном крови $(\mathrm{p}=0,01)$.

Таким образом, полученные результаты указывают на возможное участие VCAM-1 вместе с фибриногеном в формировании лейкостаза и капиллярной окклюзии, особенно в свете последних данных о связи VCAM-1 с новым маркером пролиферативной ДРП CTRPs (C1q complement/TNF-related proteins) [33].

\section{Выводы}

1. Независимо от стадии ДРП выявлена достоверная прямая линейная зависимость между VCAM-1 и фибриногеном крови $(\mathrm{p}=0,01)$.

2. Модифицирующее влияние на состояние клеточной эндотелиальной адгезии на непролиферативной стадии ДРП оказывает фактор возраста пациентов (более 60-ти лет), фактор продолжительности заболевания диабетом (свыше 10-ти лет) и особенность антидиабетической терапии (инсулинотерапия).

\section{Литература}

1. Сердюк В. Н. Морфометрические и биохимические кластеры метаболического синдрома у пациентов с сахарным диабетом 2-го типа на разных стадиях диабетической ретинопатии / В. Н. Сердюк, В. А. Ищенко // Міжнародний ендокринологічний журнал. - 2016. - Т. 7, № 7. - С. 69-74.

2. Adamiec-Mroczek J. Assessment of selected adhesion molecule and proinflammatory cytokine levels in the vitreous body of patients with type 2 diabetes-role of the inflammatory-immune process in the pathogenesis of proliferative diabetic retinopathy / J. AdamiecMroczek, J. Oficjalska-Mlynczak // Graefes Arch Clin Exp Ophthalmol. - 2008. - Vol. 246. - P. 1665-1670.

3. Aiello L. P. Diabetic retinopathy / L. P. Aiello, T. W. Gardner, G. L. King [et al.] // Diabetes Care. - 1998. - Vol. 21. - P. 143-156.

4. Antonetti D. A. Diabetic Retinopathy: Seeing Beyond Glucose-Induced Microvascular Disease / D. A. Antonetti, A. J. Barber, S. K. Bronson [et al.] // Diabetes. - 2006. - Vol. 55. - P. 2401-2411.

5. Barile G. R. Soluble cellular adhesion molecules in proliferative vitreoretinopathy and proliferative diabetic retinopathy / G. R. Barile, S. S. Chang, L. S. Park [et al.] // Curr Eye Res. - 1999. - Vol. 19. - P. 219-227.

6. Cybulsky M. I. A major role for VCAM-1, but not ICAM-1, in early atherosclerosis / M. I. Cybulsky, K. Iiyama, H. Li [et al.] // J. Clin. Invest. - 2001. Vol. 107, N 10. - P. 1255-1262.

7. Executive summary of the third report of the National Cholesterol Education Program (NCEP) Expert Panel on Detection, Evaluation and Treatment of High
Blood Cholesterol in Adults (Adult Treatment Panel III) // JAMA. - 2001. - Vol. 285. - P. 2486-2497.

8. Garner A. Histopathology of diabetic retinopathy in man /A. Garner // Eye. - 1993. - Vol. 7 (2). - P. 250-253.

9. Gho Y. S. Angiogenic activity of human soluble intercellular adhesion molecule-1 / Y. S. Gho, H. K. Kleinman, G. Sosne // Cancer Res. - 1999. - Vol. 59. - P. 5128-5132.

10. Goldberg R. B. Cytokine and cytokine-like inflammation markers, endothelial dysfunction, and imbalanced coagulation in development of diabetes and its complications / R. B. Goldberg // J Clin Endocrinol Metab. - 2009. - Vol. 94. - P. 3171-3182.

11. Grundy S. M. Diagnosis and Management of the Metabolic Syndrome / S. M. Grundy, J. I. Cleeman, S. R. Daniels [et al.] // Circulation. - 2005. - Vol. 112. - P. 2735-2752.

12. Gustavsson C. Vascular Cellular Adhesion Molecule-1 (VCAM-1) Expression in Mice Retinal Vessels Is Affected by Both Hyperglycemia and Hyperlipidemia / C. Gustavsson, C-D. Agardh, A. V. Zetterqvist [et al.] // PLoS ONE. - 2010. - Vol. 5 (9). - e12699.

13. Gustavsson C.TNF-alpha is an independent serum marker for proliferative retinopathy in type 1 diabetic patients / C. Gustavsson, E. Agardh, B. Bengtsson, C. D. Agardh // J Diabetes Complications. - 2008. - Vol. 22. - P. 309-316.

14. Hatchell D. L. Neutrophils plus capillaries in acute experimental retinal ischemia / D. L. Hatchell, C. A. Wilson, P. Saloupis // Microvasc Res. - 1994. Vol. 47. - P. 344-354.

15. Hughes J. M. Vascular leucocyte adhesion molecules unaltered in the human retina in diabetes / J. M. Hughes, A. Brink, A. N. Witmer [et al.] // Br J Ophthalmol. - 2004. Vol. 88. - P. 566-572.

16. Inzucchi S. Management of Hyperglycemia in Type 2 Diabetes, 2015: A Patient-Centered Approach: Update to a Position Statement of the American Diabetes Association and the European Association for the Study of Diabetes / S. Inzucchi, R. M. Bergenstal, J. B. Buse [et al.] // Diabetes Care. - 2015. - Vol. 38 (1). - P. 140-149.

17. Khan Z. A. Cellular signaling and potential new treatment targets in diabetic retinopathy / Z. A. Khan, S. Chakrabarti // Exp Diabetes Res. - 2007. - Vol. 2007. - P. 31867.

18. Kohner E. M. Screening for diabetic retinopathy in Europe: A field handbook / E. M. Kohner, M. Porta. Boehringer Mannheim, Italy. - 1992.

19. Konno S. Retinal blood flow changes in type I diabetes. A long-term follow-up study / S. Konno, G. T. Feke, A. Yoshida [et al.] // Invest Ophthalmol Vis Sci. - 1996. - Vol. 37. - P. 1140-1148.

20. Kurose I. Molecular determinants of reperfusion-induced leukocyte adhesion and vascular protein leakage / I. Kurose, D. C. Anderson, M. Miyasaka [et al.] // Circ Res. - 1994. - Vol. 74. - P. 336-343.

21. Larson R. S. Structure and function of leukocyte integrins / R. S. Larson, T. A. Springer // Immunological Reviews. - 1990. - Vol. 114. - P. 181-217. 
22. Libby $P$. Inflammation in atherosclerosis. / P. Libby // Nature. - 2002. - Vol. 420. - P. 868-874.

23. Limb G. A. Vascular adhesion molecules in vitreous from eyes with proliferative diabetic retinopathy / G. A. Limb, J. Hickman-Casey, R. D. Hollifield, A. H. Chignell // Invest Ophthalmol Vis Sci. - 1999. - Vol. 40. - P. 2453-2457.

24. Matsumoto K. Comparison of serum concentrations of soluble adhesion molecules in diabetic microangiopathy and macroangiopathy / K. Matsumoto, Y. Sera, Y. Ueki [et al.] // Diabet Med. - 2002. - Vol. 19. - P. 822-826.

25. Nguyen T. T. Inflammatory, Hemostatic and Other Novel Biomarkers for Diabetic Retinopathy: The Multi-Ethnic Study of Atherosclerosis / T. T. Nguyen, E. Alibrahim, F. M. A. Islam [et al.] // Diabetes Care. -2009. - Vol. 32. - P. 1704-1709.

26. Nowak M. Blood serum levels of vascular cell adhesion molecule (sVCAM-1), intercellular adhesion molecule (sICAM-1) and endothelial leucocyte adhesion molecule-1 (ELAM-1) in diabetic retinopathy / M. Nowak, T. Wielkoszynski, B. Marek [et al.] // Clin Exp Med. - 2008. - Vol. 8. - P. 159-164.

27. Sagel J. Increased platelet aggregation in early diabetes mellitus / J. Sagel, J. A. Colwell, L. Crook [et al.] // Ann Intern Med. - 1975. - Vol. 82. - P. 733-738.

28. Schlingemann R. O. Increased expression of endothelial antigen PAL-E in human diabetic retinopathy correlates with microvascular leakage / R. O. Sch- lingemann, P. Hofman, G. F. Vrensen [et al.] // Diabetologia. - 1999. - Vol. 42. - P. 596-602.

29. Takami S. High concentration of glucose induces the expression of intercellular adhesion molecule-1 in human umbilical vein endothelial cells / S. Takami, S. Yamashita, S. Kihara [et al.] // Atherosclerosis. 1998. - Vol. 138 (1). - P. 35-41.

30. Use of Glycated Haemoglobin (HbAlc) in the Diagnosis of Diabetes Mellitus. Abbreviated Report of a WHO Consultation (WHO/NMH/CHP/CPM/11.1) / World Health Organization. - Geneva: WHO. - 2011. - 25 p.

31. van Buul J. D. Endothelial signaling by Ig-like cell adhesion molecules / J. D. van Buul, E. Kanters, P. L. Hordijk // Arterioscler Thromb Vasc Biol. - 2007. Vol. 27. - P. 1870-1876.

32. Videm $V$. Soluble ICAM-1 and VCAM-1 as markers of endothelial activation / V. Videm, M. Albrigtsen // Scand J Immunol. - 2008. - Vol. 67(5). - P. 523-531.

33. Yan Z. CTRP3 is a novel biomarker for diabetic retinopathy and inhibits HGHL-induced VCAM-1 expression in an AMPK-dependent manner / Z. Yan, J. Zhao, L. Gan [et al.] // PLoS ONE. - 2017. - Vol. 12(6). - e0178253.

34. Zohlinhöfer $D$. Adhesion of monocyte very late antigen-4 to endothelial vascular cell adhesion molecule-1 induces interleukin-1beta-dependent expression of interleukin-6 in endothelial cells / D. Zohlinhöfer, K. Brand, K. Schipek [et al.] // Arterioscler. Thromb. Vasc. Biol. - 2000. - Vol. 20, N 2. - P. 353-359.

\title{
ВПЛИВ ЧИННИКІВ ПРОГРЕСІЇ ДІАБЕТИЧНОЇ РЕТИНОПАТІЇ НА ВМІСТ МАРКЕРА АДГЕЗИВНОЇ ДИСФУНКЦЇ̈ ЕНДОТЕЛІЮ УСАМ-1 В КРОВІ ЗА ЦУКРОВОГО ДІАБЕТУ 2-ГО ТИПУ ЯК КЛАСТЕРА МЕТАБОЛІЧНОГО СИНДРОМУ
}

\author{
Л. Ю. Пилипенко, В. М. Сердюк
}

Було вивчено вміст молекули судинної клітинної адгезії VCAM-1 у крові на різних стадіях діабетичної ретинопатії (ДРП) і проведено оцінку впливу чинників прогресії ДРП на їі рівень у крові при метаболічному синдромі

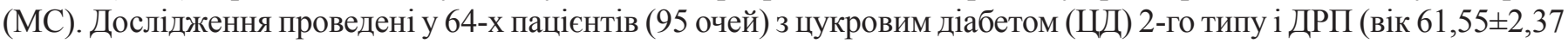

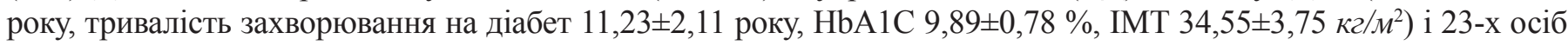

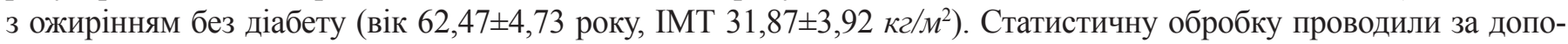
могою дисперсійного та регресійного аналізу. Виявлено, що показники VCAM-1 крові перевищували нормальні

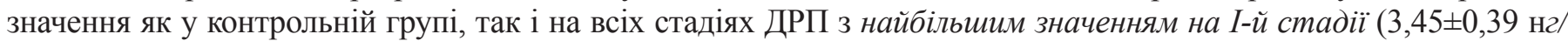
мл). Незалежно від стадії ДРП виявлено достовірну пряму лінійну залежність між VCAM-1 і фібриногеном крові $\left(\mathrm{r}=0,59 ; \mathrm{R}^{2}=35,1 \%\right.$; $\left.=0,01\right)$ і тенденцію до прямої залежності змісту VCAM-1 від тривалості захворювання на ЦД 2-го типу $\left(\mathrm{r}=0,25 ; \mathrm{R}^{2}=6,5 \%, \mathrm{p}=0,05\right)$. Зроблено висновок про можливу участь VCAM-1 разом 3 фібриногеном у формуванні лейкостазу і капілярної оклюзії, особливо на непроліферативній стадії ДРП.

Ключові слова: діабетична ретинопатія, VСАМ-1, иукровий діабет 2-го типу, метаболічний синдром.

\section{EFFECT OF DIABETIC RETINOPATHY PROGRESSION FACTORS ON THE CONTENT OF MARKER OF ADHESIVE ENDOTHELIAL DYSFUNCTION VCAM-1 IN THE BLOOD AT TYPE 2 DIABETES MELLITUS AS A CLUSTER OF METABOLIC SYNDROME}

\author{
L. Yu. Pylypenko, V. M. Serdiuk \\ State Establishment Dnipropetrovsk State Medical Academy of the Ministry of Public Health of Ukraine \\ Dnipro, Ukraine
}

Background. One of the key roles in the development of diabetic retinopathy (DRP) is capillary occlusion. As a possible mechanism of this phenomenon is the increase of the leukocytes adhesion to the endothelium due to high expression of adhesive molecules in the microcirculatory space of the retina. 
Purpose. To study the content of the vascular cell adhesion molecule VCAM-1 in the blood at different stages of the DRP.

Material and methods. The research was carried out with 64 patients ( 95 eyes) with at type 2 diabetes mellitus (T2DM), metabolic syndrome (MS) and DRP (age $61.55 \pm 2.37$ years old, length of diabetes $11.23 \pm 2.11$ years, level of HbA1C $9.89 \pm 0.78 \%$, BMI $34.55 \pm 3.75 \mathrm{~kg} / \mathrm{m} 2$ ), who were divided into 3 groups depending on the stage of DRP. Exclusion criteria for this study were: type 1 diabetics, mental disorders, age less than 18 years, severe comorbidities such as congestive heart failure, liver disease, malignancy, inflammatory process, pregnancy, or any factor affecting body weight such as hypothyroidism, corticosteroids (Cushing's syndrome), or contraceptives. Written informed consent was obtained from all subjects prior to the inclusion into the study. The ANOVA and regression analysis were used as statistical analysis.

Results. The highest value of the VCAM-1 level of blood was in the nonproliferative stage of DRP $(3.45 \pm 0.39$ $\mathrm{pg} / \mathrm{ml})$. Regardless of the stage of the DRP, a significant direct linear relationship was found between VCAM- 1 and fibrinogen of the blood $\left(\mathrm{r}=0.59, \mathrm{R}^{2}=35.1 \%, \mathrm{p}=0.01\right)$. The tendency in the direct dependence of the VCAM- 1 content and the duration of T2DM was revealed $\left(r=0.25, \mathrm{R}^{2}=6.5 \%, \mathrm{p}=0.05\right)$.

Conclusions. Possible participation of VCAM-1 together with fibrinogen in the formation of leukostasis and capillary occlusion, especially in the nonproliferative stage of DRP was traced.

Key words: diabetic retinopathy, VCAM-1, type 2 diabetes mellitus, metabolic syndrome.

Стаття надійшла до редакції 17.01.2018 p.

\title{
МОРФОМЕТРИЧНІ ОСОБЛИВОСТІ СУДИННОЇ ОБОЛОНКИ ОКА У ПАЦІЄНТІВ 3 ПРОГРЕСУЮЧОЮ МІОПІЄЮ ЗА ДАНИМИ SS-ОПТИЧНОÏ КОГЕРЕНТНОÏ ТОМОГРАФІЇ-АНГІОГРАФІЇ
}

\begin{abstract}
Метою дослідження було вивчення морфометричних змін судинної оболонки у задньому сегменті ока у пацієнтів $з$ прогресуючою міопією за даними Swept Source-оптичної когерентної томографії-ангіографії (SS-OKТА). Під спостереженням знаходились 50 пацієнтів (100 очей) 3 різними темпами прогресування міопії та 20 здорових дітей (40 очей) з еметропією.

У пацієнтів зі швидким прогресуванням міопії виявлено збільшення товщини сітківки в центрі фовеа порівняно з еметропами та зменшення товщини хоріоідеї в центрі фовеа і у папіломакулярній ділянці порівняно як із еметропами, так і з міопами 3 повільним прогресуванням міопії. При прогресуванні міопії встановлено нерівномірне зменшення товщини хоріоідеї, яке проявляється у достовірному збільшенні ретинально-хоріоідального коефіцієнта на ділянці між центром фовеа та диском зорового нерва, що у комплексі морфологічних змін заднього сегмента міопічного ока може сприяти розвитку регіонарних гемодинамічних порушень.

Ключові слова: прогресуюча міопія, судинна оболонка, оптична когерентна томографія.
\end{abstract}

Структурні особливості сітківки в макулярній та перипапілярній ділянках очного дна досить добре вивчені як при прогресуючій, так і при високій ускладненій міопії $[1,3]$. Багато праць присвячено вивченню морфометричних змін сітківки при змінах топографії макули, зумовленої формуванням задньої міопічної стафіломи [8]. Але чималий інтерес викликає роль змін судинної оболонки у міопічному оці, оскільки, згідно існуючих теорій патогенезу міопії, саме пору- шення трофіки заднього сегмента ока призводить до розвитку органічних змін сенсорного апарата ока та зниженню зорових функцій.

Сучасні методи візуалізації оболонок ока та судинного русла дозволяють вивчати морфологічні та морфометричні зміни заднього сегмента очного яблука на високому роздільному рівні. Одним із таких методів $\epsilon$ оптична когерентна томографія з ангіографією(ОКТА). Оцінка товщини судинної оболонки $з$ використанням 